\title{
Targeting assay of a fusion protein applied in enzyme prodrug therapy
}

\author{
HAO WANG, JIN-JIAN LIU and XIAO-LIANG ZHOU \\ Tianjin Key Laboratory of Radiation Medicine and Molecular Nuclear Medicine, Institute of Radiation Medicine, \\ Chinese Academy of Medical Sciences and Peking Union Medical College, Tianjin 300192, P.R. China
}

Received April 17, 2016; Accepted December 20, 2016

DOI: $10.3892 / \mathrm{ol} .2017 .5768$

\begin{abstract}
Tumor growth and metastasis are dependent on angiogenesis. The overexpression of integrin $\alpha_{v} \beta_{3}$ on angiogenic vessels and on numerous malignant human tumor cells suggests that these labeled ligands of integrin are potentially suitable for molecular imaging and in targeted therapy of tumors. In previous studies, we added a $\beta$-lactamase variant with reduced immunogenicity to the cyclic peptide RGD4C, resulting in the fusion protein RGD4C $\beta \mathrm{L}$, which is suitable for use in targeted enzyme prodrug therapy (TEPT), a promising treatment for tumors. The targeting of the aforementioned fusion protein serves an important role in TEPT. In the present study, RGD4C $\beta \mathrm{L}$ was labeled with ${ }^{125} \mathrm{I}$ and the targeting effect on integrin-positive tumors was evaluated. The results demonstrated that the ${ }^{125}$ I-RGD4C $\beta$ L protein exhibited high levels of accumulation at the tumor site and rapid renal clearance, which revealed the potency and efficiency of RGD4C $\beta \mathrm{L}$ in TEPT.
\end{abstract}

\section{Introduction}

Targeted enzyme prodrug therapy (TEPT) is a novel type of treatment for tumors (1-3), which aims to release cytotoxic agents precisely at the tumor site using pairs of enzymes and corresponding prodrugs, to avoid systemic toxicity (4). The enzymes are directed to the tumor sites by targeted molecules, including antibodies (5), mesenchymal stem cells (6), polymers $(7)$ and genes $(8,9)$. Nontoxic prodrugs, which are substrates of the enzymes, are hydrolyzed by these enzymes in order to release the cytotoxic agents $(3,10)$. Therefore, the conjugates of the targeted molecules and enzymes serve a

Correspondence to: Dr Xiao-Liang Zhou, Tianjin Key Laboratory of Radiation Medicine and Molecular Nuclear Medicine, Institute of Radiation Medicine, Chinese Academy of Medical Sciences and Peking Union Medical College, 238 Baidi Road, Nankai, Tianjin 300192, P.R. China

E-mail: zhouxiaoliang@irm-cams.ac.cn

Key words: targeted enzyme prodrug therapy, RGD4C, $\beta$-lactamase, targeting key role in TEPT. In previous studies we constructed a fusion protein, RGD4C- $\beta$-lactamase (RGD4C $\beta \mathrm{L}$ ), which contains 2 motifs: RGD4C and $\beta$-lactamase, to develop a targeted enzyme prodrug system for the treatment of tumors $(11,12)$. The targeting motif RGD4C (sequence, ACDCRGDCFCG) delivers $\beta$-lactamase, which hydrolyzes lactam-based prodrugs to release the chemotherapeutic agents at the tumor site. RGD4C is a ligand with a high affinity for integrin $\alpha_{v} \beta_{3}$, which is overexpressed on various tumor cells and angiogenic vessels. Due to the upregulation of the integrin on tumor cells, $\alpha_{v} \beta_{3}$ may be used as a target for treatment (13-18). RGD4C contains 2 disulfide bonds formed by 4 cysteine residues. The affinity of RGD4C for integrin $\alpha_{v} \beta_{3}$ is 20 -fold greater than similar peptides with a single disulfide bond, and 200-fold greater than linear peptides (13).

RGD4C is suitable for incorporation into proteins and viruses by recombinant technology (19), therefore this cyclic peptide was chosen as the targeting motif. $\beta$-lactamase exists in bacteria, exhibits no isozyme in mammals and exhibits a high specificity for hydrolyzing lactam-based prodrugs. This ensures that $\beta$-lactamase is useful for targeted enzyme prodrug systems $(20,21)$, and a variant with reduced immunogenicity and high catalytic activity was constructed for the use of $\beta$-lactamase in enzyme prodrug therapy (22). This variant was used as the catalytic motif.

Previous studies revealed that the fusion protein RGD4C $\beta \mathrm{L}$ retained a high catalytic activity on the lactam-based prodrug, and exhibited high plasma stability and low immunogenicity $(11,12)$. In the present study, RGD4C $\beta$ L was labeled with ${ }^{125} \mathrm{I}$ and the properties of the fusion protein were evaluated in vivo, to investigate the potency of the protein for use in TEPT.

\section{Materials and methods}

Materials. $\mathrm{Na}^{125}$ I was purchased from Perkin Elmer Life \& Analytical Sciences (Waltham, MA, USA), and dissolved in pH8-11 $350 \mathrm{mCi} / \mathrm{ml} \mathrm{NaOH}$ solution. Sephadex G-50 was sourced from GE Healthcare Life Sciences (Logan, UT, USA). Medium, fetal bovine serum (FBS), penicillin and streptomycin were purchased from Hyclone; GE Healthcare Life Sciences. Human sera were obtained from the Tianjin Blood Center (Tianjin, China). All procedures using human sera were approved by the Ethics Committee of the Institute 


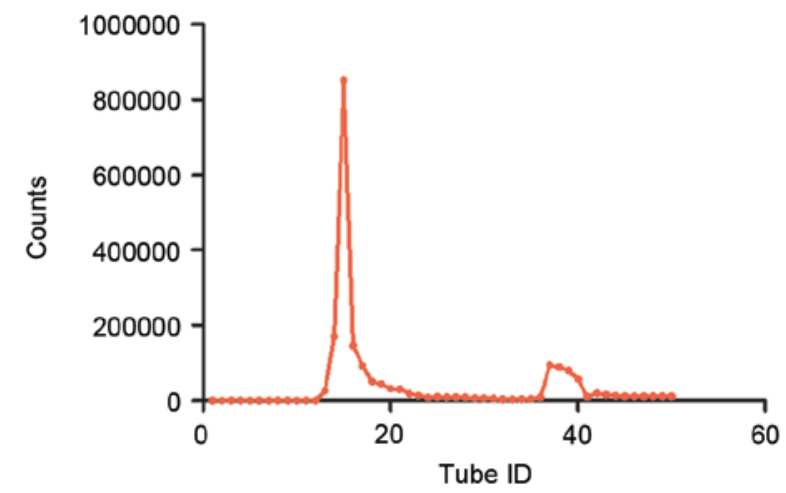

Figure 1. Separation and collection of the ${ }^{125}$ I- RGD4C $\beta$ L using column chromatography. The first peak is the ${ }^{125} \mathrm{I}-\mathrm{RGD} 4 \mathrm{C} \beta \mathrm{L}$, and the second is free ${ }^{125} \mathrm{I}$.
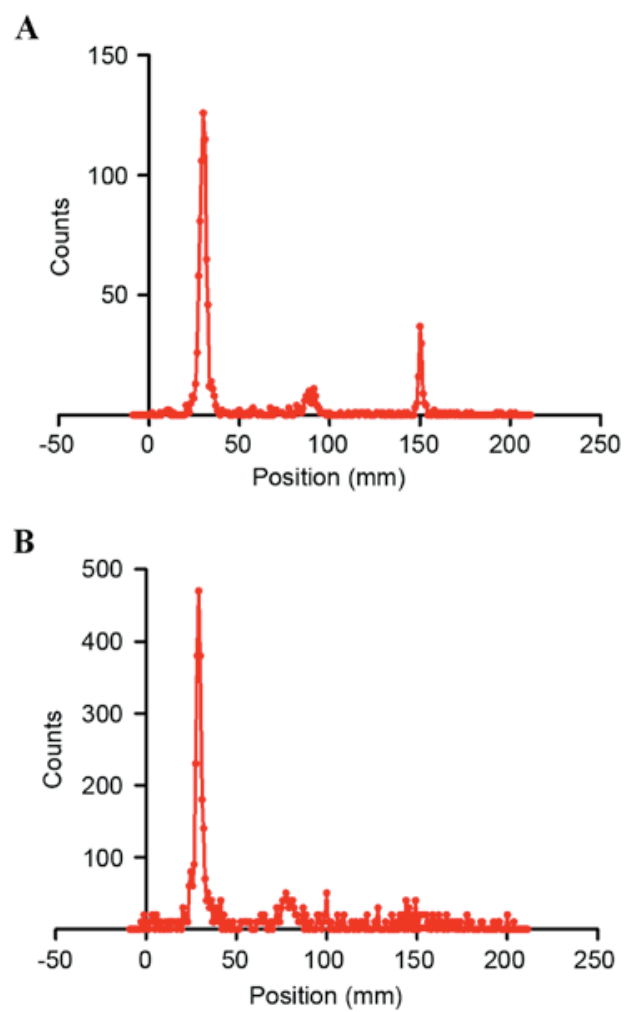

Figure 2. Labeling efficiency and radiochemical purity of the ${ }^{125} \mathrm{I}-\mathrm{RGD} 4 \mathrm{C} \beta \mathrm{L}$. The labeling rate and the radiochemical purity of the ${ }^{125} \mathrm{I}-\mathrm{RGD} 4 \mathrm{C} \beta \mathrm{L}$ were determined using radio-thin layer chromatography. (A) The labeling efficiency was calculated to be $86.5 \%$. (B) Following purification, the radiochemical purity of the ${ }^{25 I}$-RGD 4 C $\beta$ L was $100 \%$, which is suitable for the in vivo imaging and the biodistribution assay.

of Radiation Medicine of the Chinese Academy of Medical Sciences (Tianjin, China) and all studies using human sera were conducted in accordance with the regulations of the Ethics Committee of the Institute of Radiation Medicine of the Chinese Academy of Medical Sciences. Silica gel plates were purchased from Yantai JIANGYOU Silica Gel Development Co., Ltd., (Yantai, China). All other chemicals were obtained from Sigma-Aldrich; Merck KGaA (Darmstadt, Germany). The fusion protein RGD4C $\beta \mathrm{L}, 4.2 \mathrm{kDa}$, consisted of $\beta$-lactamase combined with ACDCRGDCFCG (RGD4C) by recombinant DNA technology. The fusion gene was cloned into Escherichia coli BL21 (DE3), and the protein was purified

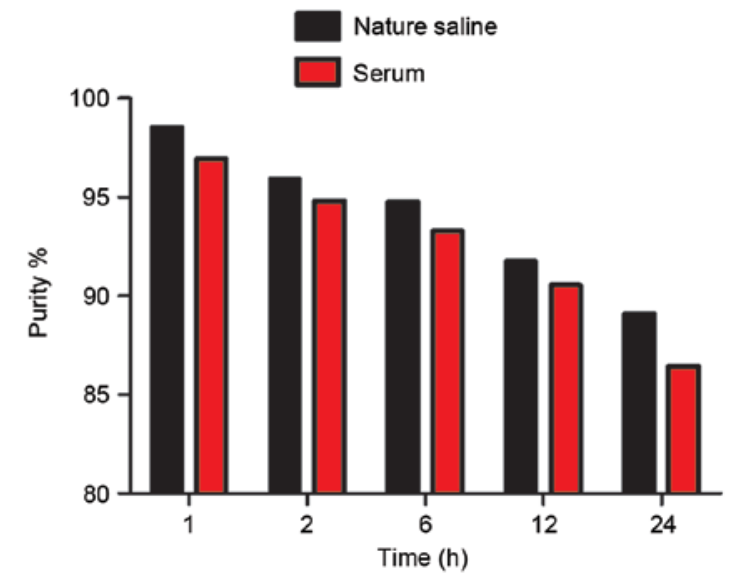

Figure 3. In vitro stability. The radiochemical purity of the ${ }^{125}$ I-RGD4C $\beta \mathrm{L}$ remained at $>89$ and $86 \%$ over $24 \mathrm{~h}$ in normal saline at room temperature, $25^{\circ} \mathrm{C}$, and in human serum at $37^{\circ} \mathrm{C}$, respectively.

with Ni-NTA resin, and was additionally confirmed by western blotting as described previously $(11,12)$.

Cell culture and animals. U87MG and A549 cells were obtained from Cell Resource Center, IBMS, CAMS/PUMC (Beijing, China) and cultured in minimum essential medium and RPMI-1640 medium, with $10 \%$ fetal bovine serum, $100 \mathrm{U} / \mathrm{ml}$ penicillin and $100 \mu \mathrm{g} / \mathrm{ml}$ streptomycin at $37^{\circ} \mathrm{C}$ in a humidified atmosphere containing $5 \% \mathrm{CO}_{2}$. Pathogen-free 6-7 week old female BALB/c nude mice were obtained from the Experimental Animal Center of Academy of Military Medical Sciences (Beijing, China). All animal procedures were approved by the Ethics Committee of the Institute of Radiation Medicine of the Chinese Academy of Medical Sciences (Tianjin, China), and all animal studies were conducted in accordance with the regulations of the Ethics Committee of the Chinese Academy of Medical Sciences (Tianjin, China).

Radioiodine labeling. A total of $3 \mu \mathrm{l} \mathrm{Na}{ }^{125} \mathrm{I}$ was dissolved in $100 \mu \mathrm{l}$ phosphate buffer (PB) buffer $(\mathrm{pH}=7.4)$ and vibrated. A total of $200 \mu \mathrm{l}$ protein solution, $0.5 \mathrm{mg}$ RGD $4 \mathrm{C} \beta \mathrm{L}$, was then added and the solution was mixed. Subsequently, $50 \mu \mathrm{l}$ chloramine-t was added and allowed to react at room temperature for $3 \mathrm{~min}$. A total of $50 \mu \mathrm{l}$ sodium pyrosulfite, $20 \mathrm{mg} / \mathrm{ml}$, was then added to stop the reaction, and the crude product was obtained. The dilution factor of ${ }^{125} \mathrm{I}$ was calculated as: Final volume/initial volume (1:134.3).

Purification and radiochemical purity. The crude product was transferred to a chromatography column filled with Sephadex G-50, which was pre-blocked by bovine serum albumin, and eluted by PB buffer $(\mathrm{pH}=7.4)$. The effluent was collected in tubes. The radioactivity in each tube was measured with a $\gamma$ counter, (2470 WIZARD2, PerkinElmer, Inc., Waltham, MA, USA), and tubes 14-17 were collected. The final product, ${ }^{125} \mathrm{I}-\mathrm{RGD} 4 \mathrm{C} \beta \mathrm{L}$, was obtained and passed through a $0.22 \mu \mathrm{m}$ Millipore filter to eliminate possible aggregates. Thin-layer chromatography (TLC) was then performed using an AR-2000 radio-TLC Imaging Scanner, Bioscan (Washington, DC, USA) to determine the labeling efficiency and the radiochemical 

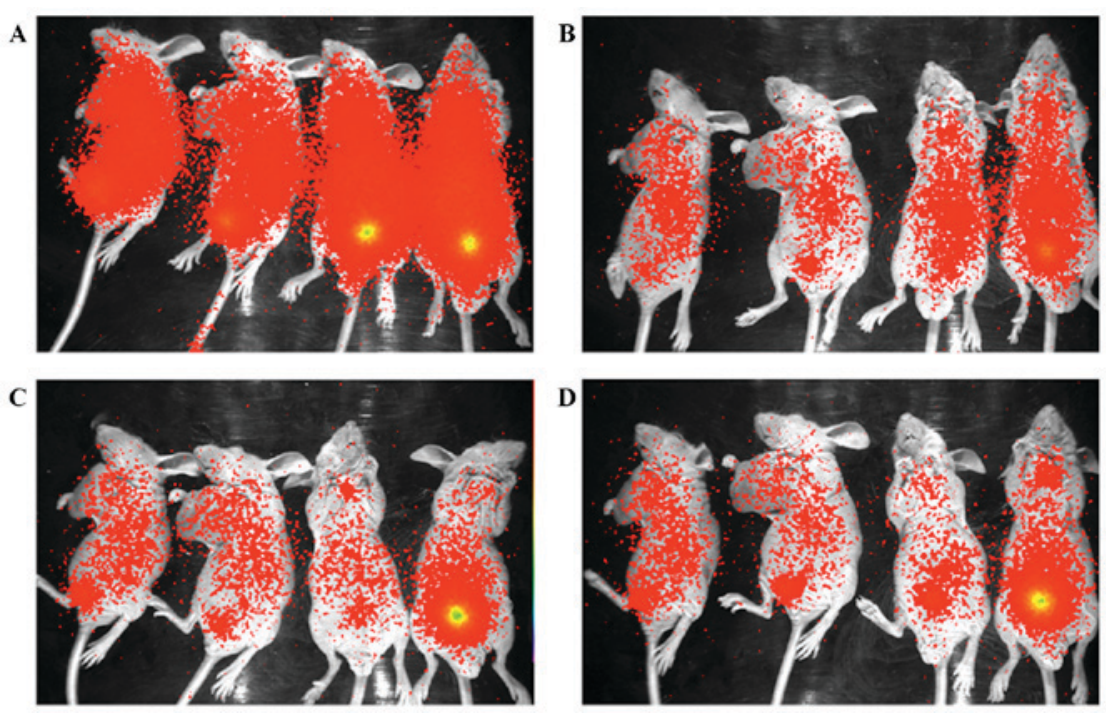

Figure 4. In vivo imaging of the ${ }^{125}$ I-RGD4C $\beta \mathrm{L}$ in nude mice bearing xenografts at (A) 2, (B) 4, (C) 6 and (D) $8 \mathrm{~h}$. The 2 mice on the left of the images were nude mice bearing A549 xenografts, and the 2 mice on the right were nude mice bearing U87MG xenografts. The levels of ${ }^{125}$ I-RGD4C $\beta L$ were reduced to background level at $24 \mathrm{~h}$ (data not included). Excretion of the ${ }^{125} \mathrm{I}$-RGD $4 \mathrm{C} \beta \mathrm{L}$ occurred through the urinary system; as demonstrated in the images, there was intense radioactivity, yellow, in the bladder, which was higher than in the other organs of several mice.

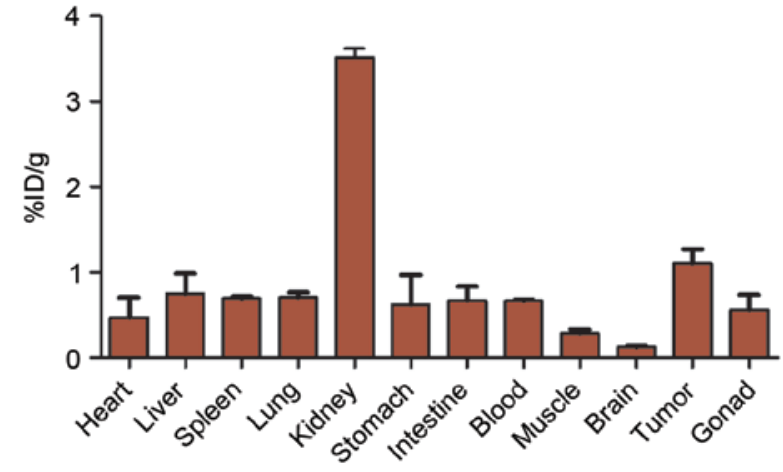

Figure 5. Biodistribution of ${ }^{125} \mathrm{I}-\mathrm{RGD} 4 \mathrm{C} \beta \mathrm{L}$ in nude mice bearing A549 xenografts. The data were measured as $\% \mathrm{ID} / \mathrm{g}$, and were expressed as the mean value \pm standard deviation, $n=4$. The highest dose percentile was in the kidneys, which is consistent with the whole-body imaging results and indicates that the fusion protein was metabolized through the urinary system. The uptake of ${ }^{125}$ I-RGD $4 \mathrm{C} \beta \mathrm{L}$ in the tumors was increased compared with in the blood and the muscle tissues, with the ratios of ${ }^{125}$ I-RGD4C $\beta L$ levels in tumor vs. blood and in tumor vs. muscle measuring 1.7 and 3.8, respectively, which illustrated the suitability of the ${ }^{125}$ I-RGD4C $\beta \mathrm{L}$ as an imaging agent for treatment monitoring, and confirmed the viability of RGD4C $\beta \mathrm{L}$ as a targeted enzyme within targeted enzyme prodrug therapy.

purity of the ${ }^{125}$ I-RGD $4 \mathrm{C} \beta \mathrm{L}$, directly subsequent to labeling and purification, using acetone as a developing solvent.

In vitro stability. In total, 2 portions of $100 \mu 1$ of the ${ }^{125} \mathrm{I}-\mathrm{RGD} 4 \mathrm{C} \beta \mathrm{L}$ were added to $500 \mu \mathrm{l}$ normal saline at room temperature $\left(25^{\circ} \mathrm{C}\right)$ and $500 \mu 1$ human serum at $37^{\circ} \mathrm{C}$ respectively. The radiochemical purities were assayed by TLC at 1 , 2,6 and $24 \mathrm{~h}$.

Tumor model and in vivo imaging. In the right flank (armpit region) of 6-7 week old BALB/c nude mice, $5 \times 10^{6}$ U87MG or A549 cells were implanted. The tumors were allowed to grow for 3 weeks subsequent to inoculation, then the animals received $7 \mu \mathrm{Ci}$ of the ${ }^{125} \mathrm{I}-\mathrm{RGD} 4 \mathrm{C} \beta \mathrm{L}$, in $200 \mu \mathrm{l} \mathrm{PBS}$, via the lateral tail vein under anesthesia. The images of the mice were taken using a small-animal imaging system (Kodak In-Vivo Imaging System Fx Pro, Kodak, Rochester, NY, USA) at several time points.

Biodistribution. A total of 4 mice bearing A549 xenografts were injected with $7 \mu \mathrm{Ci}$ of the ${ }^{125} \mathrm{I}-\mathrm{RGD} 4 \mathrm{C} \beta \mathrm{L}$ via the tail vein. At $6 \mathrm{~h}$ post-injection, mice were anaesthetized, bled and dissected. The blood, tumor, heart, liver, spleen, lung, kidney, stomach, intestine, muscle, brain and gonad, were weighed and measured for radioactivity using a $\gamma$ counter. The uptake of the ${ }^{125} \mathrm{I}$-RGD4C $\beta \mathrm{L}$ was expressed as the percentage injected dose per gram body weight $(\% \mathrm{ID} / \mathrm{g})$.

Statistical analysis. Data were analyzed using Prism software (version 5.01; GraphPad Software, Inc., La Jolla, CA, USA). The Student's t-test was used for statistical analysis of all data. Two-sided significance levels were calculated and $\mathrm{P}<0.05$ was considered to indicate a statistically significant difference. Values are presented as the mean \pm standard deviation of triplicate experiments.

\section{Results}

Purification and radiochemical purity. Following radio-labelling, the ${ }^{125}$ I-RGD4C $\beta \mathrm{L}$ was purified using Sephadex G-50 chromatography and the fractions (tubes 14-17) were collected as the final product, as demonstrated in Fig. 1. The radiolabeling efficiency and radiochemical purity were assayed on silica gel plates, using acetone as the developing solvent. The radiolabeling efficiency in the present experiment was $82.6 \%$, as illustrated in Fig. $2 \mathrm{~A}$. The radiochemical purity of final product was almost 100\%, as demonstrated in Fig. 2 B.

In vitro stability. Radiochemical purity of the ${ }^{125} \mathrm{I}-\mathrm{RGD} 4 \mathrm{C} \beta \mathrm{L}$ remained $>89$ and $86 \%$ periodically, over $24 \mathrm{~h}$ in normal saline at room temperature and in human serum at $37^{\circ} \mathrm{C}$, as 
illustrated in Fig. 3, which demonstrated a positive prognosis for in vivo application.

In vivo imaging. Nude mice bearing A549 and U87MG xenografts were injected with $7 \mu \mathrm{Ci}$ of the ${ }^{125} \mathrm{I}-\mathrm{RGD} 4 \mathrm{C} \beta \mathrm{L}$. Fig. 4 demonstrated the results of the in vivo imaging at several time points. The colors reflected the distribution of the ${ }^{125} \mathrm{I}-\mathrm{RGD} 4 \mathrm{C} \beta \mathrm{L}$ in mice, where red demonstrated tumor uptake of ${ }^{125} \mathrm{I}-\mathrm{RGD} 4 \mathrm{C} \beta \mathrm{L}$ and yellow demonstrated excretion of ${ }^{125} \mathrm{I}-\mathrm{RGD} 4 \mathrm{C} \beta \mathrm{L}$ by the urinary system.

Biodistribution. The results of the biodistribution of ${ }^{125} \mathrm{I}-\mathrm{RGD} 4 \mathrm{C} \beta \mathrm{L}$ are demonstrated in Fig. 5, and the data is presented as the percentage dose per gram tissue (\%ID/g). The distribution of ${ }^{125} \mathrm{I}-\mathrm{RGD} 4 \mathrm{C} \beta \mathrm{L}$ in distinct organs was evaluated by measuring the radioactivity density of each organ at $6 \mathrm{~h}$ following intravenous injection. Fig. 5 demonstrates the radioactivities of the primary organs. The highest density of the ${ }^{125} \mathrm{I}-\mathrm{RGD} 4 \mathrm{C} \beta \mathrm{L}$ was observed in the kidney, which suggested renal clearance. The concentration of tumor ${ }^{125} \mathrm{I}-\mathrm{RGD} 4 \mathrm{C} \beta \mathrm{L}$ was increased compared with the blood and muscle.

\section{Discussion}

Targeted enzymes are useful in tumor therapy as they convert nontoxic prodrugs into chemotherapeutic agents at the precise tumor sites, avoiding systemic exposure and minimizing side effects, and catalyzing the self-quenching substrate in in vivo fluorescence imaging $(22,23)$. The key characteristics of targeted enzymes are their biodistribution and pharmacokinetic properties. These enzymes should exhibit a high uptake level at the tumor site, and should degrade rapidly in the blood and normal tissues, converting the prodrugs in a site-specific manner $(2,3,24,25)$. Therefore, it is important to investigate the in vivo distribution and clearance mechanisms of these enzymes.

The present study constructed RGD4C $\beta \mathrm{L}$ as a targeted enzyme for use in TEPT. Previous studies have demonstrated that RGD $4 \mathrm{C} \beta \mathrm{L}$ possesses a potent catalytic function, low immunogenicity and high stability (11). Flow cytometric studies have also revealed that the targeting effect of RGD4C $\beta \mathrm{L}$ was equal to that of RGD4C, and is blocked by RGD4C in vitro (12). Immunofluorescent staining of fluorescein isothiocyanate-RGD4C $\beta \mathrm{L}$ and a binding assay of ${ }^{99 \mathrm{~m}} \mathrm{Tc}-\mathrm{RGD} 4 \mathrm{C} \beta \mathrm{L}$ confirmed the affinity and specificity of RGD4C $\beta \mathrm{L}$ on tumor cells, and that the ${ }^{99 \mathrm{~m}} \mathrm{Tc}-\mathrm{RGD} 4 \mathrm{C} \beta \mathrm{L}$ exhibited a short half-life in rats. The half-lives of distribution and elimination of ${ }^{99 \mathrm{~m}} \mathrm{Tc}-\mathrm{RGD} 4 \mathrm{C} \beta \mathrm{L}$ were 7.8 and $21.9 \mathrm{~min}$, respectively (26), which are favorable for its use in TEPT. In the present study, in vivo imaging and biodistribution assays using radioiodine labeling technology were performed, and revealed that RGD4C $\beta \mathrm{L}$ may be efficiently labeled with ${ }^{125} \mathrm{I}$, and ${ }^{125} \mathrm{I}-\mathrm{RGD} 4 \mathrm{C} \beta \mathrm{L}$ exhibited good stability in plasma. Biodistribution assays demonstrated that ${ }^{125} \mathrm{I}-\mathrm{RGD} 4 \mathrm{C} \beta \mathrm{L}$ enters tumor sites and remains at an acceptable level within the tumor in comparison with normal tissues. ${ }^{125} \mathrm{I}-\mathrm{RGD} 4 \mathrm{C} \beta \mathrm{L}$ is also removed rapidly from the body by renal excretion; at $24 \mathrm{~h}$ post-injection, the radioactivity levels in mice were reduced to background levels (data not included). These results revealed the potency of RGD4C $\beta \mathrm{L}$ within TEPT, and demonstrated the use of ${ }^{125} \mathrm{I}-\mathrm{RGD} 4 \mathrm{C} \beta \mathrm{L}$ in molecular imaging for treatment monitoring, and the optimization of doses and time schedules in TEPT.

\section{Acknowledgements}

The present study was supported by the National Natural Science Foundation of China (grant nos. 81301983, 81502759), The IRM-CAMS Research Fund (grant no. 1529) and Natural Science Foundation of Tianjin (grant no. 15JCQNJC45800).

\section{References}

1. Guillen KP, Kurkjian C and Harrison RG: Targeted enzyme prodrug therapy for metastatic prostate cancer - a comparative study of L-methioninase, purine nucleoside phosphorylase, and cytosine deaminase. J Biomed Sci 21: 65, 2014.

2. Krais JJ, De Crescenzo O and Harrison RG: Purine nucleoside phosphorylase targeted by annexin $\mathrm{v}$ to breast cancer vasculature for enzyme prodrug therapy. PLoS One 8: e76403, 2013.

3. Schellmann N, Deckert PM, Bachran D, Fuchs H and Bachran C: Targeted enzyme prodrug therapies. Mini Rev Med Chem 10: 887-904, 2010.

4. Tietze LF and Schmuck K: Prodrugs for targeted tumor therapies: Recent developments in ADEPT, GDEPT and PMT. Curr Pharm Des 17: 3527-3547, 2011.

5. Schellmann N, Panjideh H, Fasold P, Bachran D, Bachran C, Deckert PM and Fuchs H: Targeted tumor therapy with a fusion protein of an antiangiogenic human recombinant $\mathrm{scFv}$ and yeast cytosine deaminase. J Immunother 35: 570-578, 2012.

6. Nouri FS, Wang X and Hatefi A: Genetically engineered theranostic mesenchymal stem cells for the evaluation of the anticancer efficacy of enzyme/prodrug systems. J Control Release 200: 179-187, 2015.

7. Satchi-Fainaro R, Hailu H, Davies JW, Summerford C and Duncan R: PDEPT: Polymer-directed enzyme prodrug therapy. 2. HPMA copolymer-beta-lactamase and HPMA copolymer-C-Dox as a model combination. Bioconjug Chem 14: 797-804, 2003.

8. Williams EM, Little RF, Mowday AM, Rich MH, Chan-Hyams JV, Copp JN, Smaill JB, Patterson AV and Ackerley DF: Nitroreductase gene-directed enzyme prodrug therapy: Insights and advances toward clinical utility. Biochem J 471: 131-153, 2015.

9. Carruthers KH, Metzger G, During MJ, Muravlev A, Wang C and Kocak E: Gene-directed enzyme prodrug therapy for localized chemotherapeutics in allograft and xenograft tumor models. Cancer Gene Ther 21: 434-440, 2014.

10. Bagshawe KD: Targeting: The ADEPT story so far. Curr Drug Targets 10: 152-157, 2009.

11. Zhou X, Wang H, Shi P and Meng AM: Characterization of a fusion protein of RGD4C and the $\beta$-lactamase variant for antibody-directed enzyme prodrug therapy. Onco Targets Ther 7: 535-541, 2014.

12. Wang H, Shi PJ, Wu MF, Li N,Zhou XL and Fan FY: Construction, expression and functional characterization of the $\beta$-lactamase with $\alpha v$ integrin ligands. Protein Pept Lett 17: 1562-1565, 2010.

13. Koivunen E, Wang B and Ruoslahti E: Phage libraries displaying cyclic peptides with different ring sizes: Ligand specificities of the RGD-directed integrins. Biotechnology (N Y) 13: 265-270, 1995.

14. Huang P,Wu J,Li X,Liu X,Li Y and Cui G: RGD peptide-pegylated PLLA nanoparticles containing epirubicin hydrochloride exhibit receptor-dependent tumor trafficking in vitro and in vivo. Pharm Res 32: 2328-2343, 2015.

15. Wang H, Chen K, Cai W, Li Z, He L, Kashefi A and Chen X: Integrin-targeted imaging and therapy with RGD4C-TNF fusion protein. Mol Cancer Ther 7: 1044-1053, 2008.

16. Zheng Y, Ji S, Tomaselli E, Yang Y and Liu S: Comparison of biological properties of (111)In-labeled dimeric cyclic RGD peptides. Nucl Med Biol 42: 137-145, 2015.

17. Stott Reynolds TJ, Schehr R, Liu D, Xu J, Miao Y, Hoffman TJ, Rold TL, Lewis MR and Smith CJ: Characterization and evaluation of DOTA-conjugated Bombesin/RGD-antagonists for prostate cancer tumor imaging and therapy. Nucl Med Biol 42: 99-108, 2015. 
18. He X, Alves CS, Oliveira N, Rodrigues J, Zhu J, Bányai I, Tomás H and Shi X: RGD peptide-modified multifunctional dendrimer platform for drug encapsulation and targeted inhibition of cancer cells. Colloids Surf B Biointerfaces 125: 82-89, 2015.

19. Temming K, Schiffelers RM, Molema G and Kok RJ: RGD-based strategies for selective delivery of therapeutics and imaging agents to the tumour vasculature. Drug Resist Updat 8: 381-402, 2005.

20. Roberge M, Estabrook M, Basler J, Chin R, Gualfetti P, Liu A Wong SB, Rashid MH, Graycar T, Babé L and Schellenberger V: Construction and optimization of a CC49-based scFv-beta-lactamase fusion protein for ADEPT. Protein Eng Des Sel 19: 141-145, 2006.

21. Cartwright SJ and Waley SG: Purification of beta-lactamases by affinity chromatography on phenylboronic acid-agarose. Biochem J 221: 505-512, 1984.

22. Bhaumik S: Advances in imaging gene-directed enzyme prodrug therapy. Curr Pharm Biotechnol 12: 497-507, 2011.
23. Bhaumik S, Sekar TV, Depuy J, Klimash J and Paulmurugan R: Noninvasive optical imaging of nitroreductase gene-directed enzyme prodrug therapy system in living animals. Gene Ther 19: 295-302, 2012.

24. Van Rite BD, Krais JJ, Cherry M, Sikavitsas VI, Kurkjian C and Harrison RG: Antitumor activity of an enzyme prodrug therapy targeted to the breast tumor vasculature. Cancer Invest 31: 505-510, 2013.

25. Bhatia J, Sharma SK, Chester KA, Pedley RB, Boden RW, Read DA, Boxer GM, Michael NP and Begent RH: Catalytic activity of an in vivo tumor targeted anti-CEA scFv::Carboxypeptidase G2 fusion protein. Int J Cancer 85: 571-577, 2000.

26. Wang H, Zhou XL, Long W, Liu JJ and Fan FY: A Fusion Protein of rgd $4 \mathrm{c}$ and $\beta$-lactamase has a favorable targeting effect in its use in antibody directed enzyme prodrug therapy. Int J Mol Sci 16: 9625-9634, 2015. 